\title{
Post Traumatic Intradiploic Leptomeningeal Cyst in a 2 Year Old Child
}

Karuna Tamrakar Karki ${ }^{\star}$, Pramod K Chaudhary, Sunil Munakomi, Binod Bhattarai and lype Cherian

Department of Neurosurgery, Kathmandu University teaching hospital, Chitwan, Nepal

*Corresponding author: Karuna Tamrakar Karki, Department of Neurosurgery College of Medical Sciences Bharatpur -23, Kathmandu University teaching hospital Chitwan, Nepal; E-mail : tamrakarkaruna@gmail.com

Received date: Sep 23, 2015; Accepted date: Oct 17, 2015; Published date: Oct 22, 2015

Copyright: (c) 2015 Karki KT, et al. This is an open-access article distributed under the terms of the Creative Commons Attribution License, which permits unrestricted use, distribution, and reproduction in any medium, provided the original author and source are credited.

\begin{abstract}
Growth of post taumatic intradiploic leptomeningeal cyst following head trauma is one of the rare complications of skull fractures seen mainly in infancy and toddlers. It is characterized by progressive diastatic enlargement of the fracture line with progressively increasing pulsatile cystic mass filled with cerebrospinal fluid in diploic space. Herein, we report a case of 2 year old boy presented with huge soft, non-tender pulsatile growing mass on the frontal aspect 9 months after sustaining head injury. CT imaging delineated it as a post traumatic intradiploic leptomeningeal cyst in frontal bone secondary to superior sagittal suture diastasis. Cyst was meticulously excised from superior sagittal sinus followed by durocranioplasty.
\end{abstract}

Keywords: Growing skull fractures; Head trauma; Intradiploic space; Leptomeningeal cyst; Suture diastasis

\section{Introduction}

Post traumatic leptomeningeal cysts are typical sequel of growing skull fractures (GSFs). They were first described by John Howship in 1816 and represent less than $0.05 \%$ to $1.6 \%$ [1]. Among all GSF protrusion of leptomeninges in intradiploic location after head trauma has been occasionally reported in the literature and 21 cases have been reported [2]. These posttraumatic, growing, pulsatile cystic lesions are among the rare complications after sustaining head trauma to the skull bones in pediatric age groups. GSFs usually occur during infancy and early childhood who are younger than 3 year old [3]. Growth of skull fractures are the consequence of dural tear involving both layers below the fracture ends and entrapment of arachnoid layer at the time of head trauma. Therefore craniocerebral erosion is another term given which goes often misdiagnosed [4]. Intractable seizure and focal neurological deficits have been reported associated with GSF $[3,5]$ However late and variable presentation usually leads to delay and improper treatment that could worsen the clinical condition Herein we present a 2 year old boy who developed intradiplioc leptomeningeal cyst after the head trauma. Aim of this clinical study is to elucidate the clinioradiological presentation and pathophysiological staging of intradiplioc leptomeningeal cyst.

\section{Case Report}

A 2 year old boy presented with a history of sustaining head injury after fall from the 2 stored building 9 months back. Boy had a progressively increasing asymptomatic swelling over the mid frontal region since the period of head trauma. He was initially managed conservatively with blood transfusion for low hemoglobin level. On examination he was conscious with no history of abnormal body movements, nausea, vomiting, or any discharge from the nose or ear. On local examination, cyst was $10 \mathrm{~cm}$ by $6 \mathrm{~cm}$ non-tender compressible and pulsatile. Fractured bony margins with a gap in between were palpable. On initial CT (taken on day 1 of trauma) review frontal soft tissue swelling and linear fracture of the frontal bone at the midline with superior sagittal suture diastasis was noted (Figure 1a) Fracture was extending into left supraorbital roof (Figure 1b). Brain parenchyma underneath was contused and edematous with presence of subdural hematoma in left frontal convexity. Subgaleal swelling was not distinctly enlarging although extracalvarial herniation of gliotic cerebral tissue was noted in subsequent CT imaging repeated after 3rd day of trauma (Figure 1c). He got discharged from the hospital after swelling started resolving. However after 6 months of trauma, his parents noticed increasing swelling of pulsatile mass over previous fracture site. CT Imaging review after 6 months of injury clearly showed beginning of widening gap in diploic region between 2 fracture edges and subgaleal cystic mass filled with CSF and gliotic brain tissue (Figure 2a). CT imaging after 9 months of trauma clearly showed significantly separated inner and outer tables of frontal bone (Figure 2b). Herniation of gliotic cerebral tissue into the cystic mass lying between diploic space (Figure 2c) and frontal horn of left lateral ventricle was pulled up towards the cavarial defect. Boy was operated after informed consent. Outer table was bitten off and evenly surfaced. Cyst was excised after careful delineation of attachment into posterior part of superior sagittal sinus. Dural defect was repaired by pericranial layer. Bone defect was repaired with bone fragments removed from the outer table of frontal bone (Figure 3b). Postoperatively close-fitting crepe bandage was applied for 2 months to prevent cystic recurrence and to accelerate early bony fusion. On 6 and 9 months clinical follow up, no recurrence was noted (Figure $3 \mathrm{c}$ and $3 \mathrm{~d}$ ). 

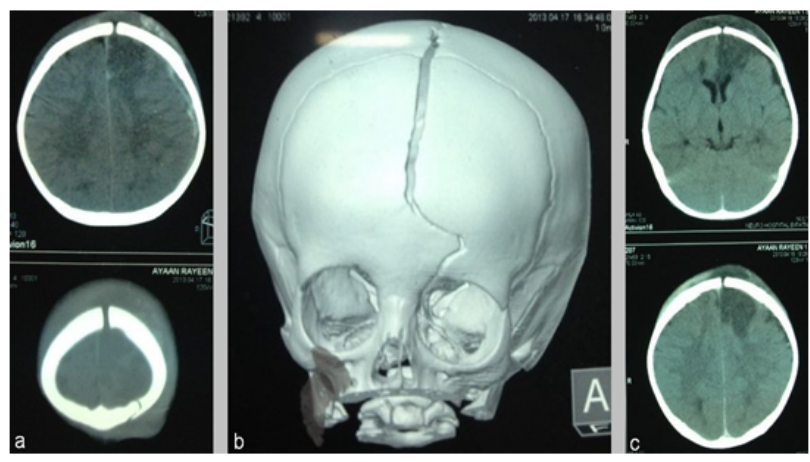

Figure 1: a: CT scan taken on day 1 of trauma shows cephalhematoma with superior sagittal sinus diastasis, underlying contusion and thin subdural hematoma; b: 3D reconstruction CT of skull showing superior sagittal sinus diastasis and fracture line extending to left supraorbital roof; c: CT taken on day 3 of trauma shows no increase in cephalhematoma and resolving subdural hematoma and contusion.

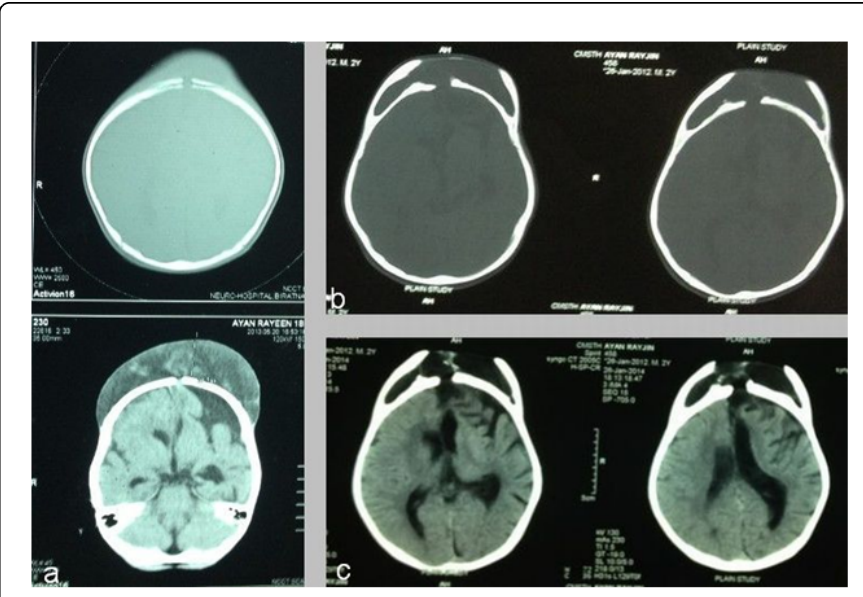

Figure 2: a: CT after 6 months of trauma shows showed beginning of separation of diplioc space in both fracture margins with subgaleal cystic mass filled with CSF and gliotic brain tissue. b: CT after 9 months of trauma shows wide separation of inner and outer tables of frontal bone. c: Herniation of gliotic cerebral tissue into the cystic mass lying between diploic space and left lateral ventricle was pulled towards the cyst.
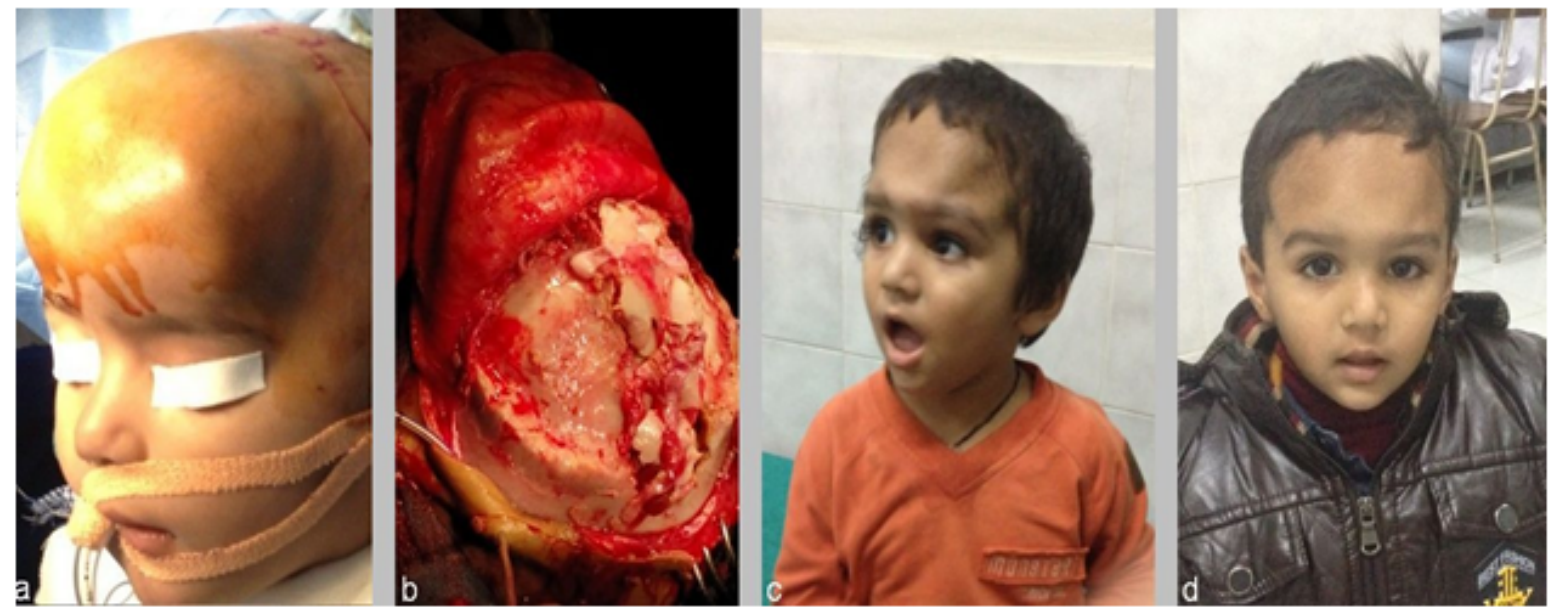

Figure 3: a: Boy before the surgery with huge cystic mass on the frontal region; b: Outer table is bitten off and defect is reconstructed with autologous bone fragments; c: Boy after 3 months follow up after durocranioplasty; d: 9 months clinical follow up.

\section{Discussion}

Postnatal growth and differentiation of the brain and skull vault occurs within the first 2 years of life. By the end of this time inner and outer calvarial tables, diploic spaces and vascular markings become distinct [6]. Head injury is the leading cause of death and disability in children mostly affecting children less than 16 year old [1-4,7]. The most common causes of head injury are falls and road traffic accidents and less common causes are child abuse, physical assaults, instrumental delivery, cranial vault repair and sports injuries [1-7]. Linear skull fractures constitutes round $7 \%-40 \%$ in all pediatric head injury $[7,8]$. They usually have no clinical significance and require no specific treatment. In children aged between 0 and 3 years old, diastatic skull fractures carry a high risk of transforming into a GSF which occurs gradually over a period ranging from sever months to years. There are two types of growing skull fractures. 1. Active type where intracranial pressure (ICP) is raised and pulsatile growing mass is felt between two edges of bony defect. 2. Arrested type where ICP is normal and slack or sunken gap is felt in bony defect. Several pathogenesis have been described for the formation of leptomeningocele after traumatic brain injury in children $[1,2]$. In 1938 Dyke was the first to coin the term "leptomeningeal cyst" when he suggested that after head trauma with skull fracture, loculated fluid filled cysts develop and owing to pulsations of the brain the overlying bone is absorbed [6]. Dura mater has two layers, outer periosteal layer 
and inner meningeal layer. Outer layer being in close contact with periosteum in children formation of extradural hematoma is rare. This is the major cause of dura mater tear during linear skull fractures. Malleable skull, increase brain volume, firmly attached dura are the main causes in progression of GSFs. Fracture without dural laceration never progress into GSFs. Development of leptomeningocele in intradiplioc location is one of the rare consequences of growing skull fractures [2]. Common locations are cranial vault either frontal or parietal regions [7]. Due to ordinary clinicoradiological presentation in initial stage of trauma, early diagnosis is usually missed. Progression of GSFs is detailed in three following stages. Stage 1 develops in between time of injury to just before enlargement so it is also defined as pre phage of GSFs [1]. The most useful clues for the diagnosis of GSFs are clinical and radiological findings. In stage 1 , following conditions have been assumed to be at high risk. 1. Linear skull fracture with dural tear. 2. Herniation of brain tissue or arachnoid layer through the bony defect. 3. Suture diastasis of more than $4 \mathrm{~mm}$ [9]. These typical presentations were obvious in our patient. This particular stage is confusing for the possibility of the fracture lines turning into GSFs. Patients who meet first 2 conditions or if present only with condition number 3, patient may have the high risk of developing post traumatic leptomeningeal cyst [9]. Bone defect will not be noticeable and no tense pulsatile swelling is seen in this stage. Tissue interposition between two fracture margins is the main culprit for slowing the osteoblastic migration and hampers in healing process [10]. This ultimately results into bone reabsorption and thinning of bony edges and further craniocerebral erosion takes place. Stage 2 is the early phage of GSFs. It usually becomes distinct after 2-3 months of initial trauma. Gradual enlargement of the fracture occurs with or without scalp swelling. Presence of pulsatile growing mass may be visible during crying. However bony defect is usually small without skull vault deformity. Child may or may not have neurological deficit. This is the crucial phase of identifying the growing skull fracture and treat accordingly for better result [11]. Increase pulsation produces continuous pressure over the fracture edges. This process further helps in bone reabsorption and enlargement of fracture edges including separation of diploic space [12]. Stage 3 is the late or progressive phage of GSFs. After the initial trauma these fractures enlarge with time. Time lag between initial stage and beginning of formation of leptomeningeal cyst is usually between months to years [13]. Clinical diagnosis is made on months to year old history of head trauma followed by progressive enlargement of skull fracture. Presence of progressively enlarging pulsatile non tender cystic mass is the pathognomonic of growing skull fractures. During $3^{\text {rd }}$ stage bony defect becomes rapidly larger and reach their full size within a couple of months. Skull deformity and neurological problems become prominent if patient is left untreated [14].

\section{Conclusion}

Ignorance of simple linear skull fracture, suture diastasis in closed head injury in young children can produce growing skull fractures as a late complication of head injury. Recognizing unusual progression of the disease is very crucial. To identify post traumatic leptomeningeal cyst as a delayed complication in pediatric populations, frequent clinical and radiological reviews with latest neuroimaging strategy showed be done in suspected cases.

\section{References}

1. Liu XS, You C, Lu M, Liu JG (2012) Growing skull fracture stages and treatment strategy. J Neurosurg Pediatr 9: 670-675.

2. Agrawal D, Mishra S (2010) Post-traumatic intradiploic pseudomeningocele. Indian Pediatr 47: 271-273.

3. Singla N, Gupta SK (2010) The natural history of an untreated growing skull fracture: an unusual case. Pediatr Neurosurg 46: 76-79.

4. Ersahin Y, Gülmen V, Palali I, Mutluer S (2000) Growing skull fractures (craniocerebral erosion). Neurosurg Rev 23: 139-144.

5. Kumar R, Sahu RN, Srivastav AK, Mehrotra A, Das KK (2012) An unusual case of post-traumatic intradiploic leptomeningeal cyst and review of the literature. Neurol India 60: 245-247.

6. Kingsley D, Till K, Hoare R (1978) Growing fractures of the skull. J Neurol Neurosurg Psychiatry 41: 312-318.

7. Ciurea AV, Gorgan MR, Tascu A, Sandu AM, Rizea RE (2011) Traumatic brain injury in infants and toddlers, 0-3 years old. J Med Life 4: 234-243.

8. Alexiou GA, Sfakianos G, Prodromou N (2011) Pediatric head trauma. J Emerg Trauma Shock 4: 403-408.

9. Ellis TS, Vezina LG, Donahue DJ (2000) Acute identification of cranial burst fracture: comparison between CT and MR imaging findings. AJNR Am J Neuroradiol 21: 795-801.

10. Iyer SG, Saxena P, Kumhar GD (2003) Growing skull fractures. Indian Pediatr 40: 1194-1196.

11. Wang X, Li G, Li Q, You C (2013) Early diagnosis and treatment of growing skull fracture. Neurol India 61: 497-500.

12. Kingsley D, Till K, Hoare R (1978) Growing fractures of the skull. J Neurol Neurosurg Psychiatry 41:312-318.

13. Leung GK, Chan KH, Hung KN (2011) Growing skull fracture in an adult nine years after blunt head trauma. J Clin Neurosci 18: 855-857.

14. Piatt JH Jr (2004) Recognizing neurosurgical conditions in the pediatrician's office. Pediatr Clin North Am 51:237-270. 